Article

\title{
Influence of General Mineral Condition on Collagen-Guided Alveolar Crest Augmentation
}

\author{
Marcin Kozakiewicz ${ }^{\mathbb{D}}$, Piotr Szymor and Tomasz Wach * \\ Department of Maxillofacial Surgery, Medical University in Lodz, Pl. Hallera 1, 90-647 Lodz, Poland; \\ marcin.kozakiewicz@umed.lodz.pl (M.K.); piotr.szymor@umed.lodz.pl (P.S.) \\ * Correspondence: tomaszwach.90@gmail.com; Tel.: +48-42-6393068
}

Received: 14 July 2020; Accepted: 12 August 2020; Published: 18 August 2020

\begin{abstract}
The local regeneration of bone defects is regulated by general hormone, enzyme, ion, and vitamin levels. General diseases and dysregulation of the human mineral system can impact this process, even in alveolar crest. The aim of this study is to investigate a relation between bone density, measured in two-dimensional X-rays, and general mineral condition of patients. The study included 42 patients on whom tooth extractions were performed. Data were divided into two groups: the region where collagen scaffold (BRM) was used and the reference region of intact normal bone (REF). Two-dimensional intraoral radiographs were taken in all cases just after the surgery $(00 \mathrm{M})$ and 12 months later $(12 \mathrm{M})$. Thyrotropin (TSH), parathormone (PTH), $\mathrm{Ca}^{2+}$ in serum, HbA1c, vitamin $25(\mathrm{OH}) \mathrm{D}_{3}$, and spine densitometry were checked. Digital texture analysis in MaZda 4.6 software was done. Texture Index (TI: BRM $1.66 \pm 0.34$ in $00 \mathrm{M}, 1.51 \pm 0.41$ in $12 \mathrm{M}$, and REF 1.72 \pm 0.28 ) and Bone Index (BI: BRM $0.73 \pm 0.17$ in $00 \mathrm{M}, 0.65 \pm 0.2241$ in $12 \mathrm{M}$, and REF $0.80 \pm 0.14$ ) were calculated to evaluate bone regeneration process after 12 months of healing (TI $(p<0.05)$ and BI $(p<0.01)$ are lower in BRM $12 \mathrm{M}$ than in REF). This showed a relation between BI and TSH $\left(\mathrm{R}^{2}=26 \%\right.$, $p<0.05)$, as well as a between BI and patient age $\left(R^{2}=65 \%, p<0.001\right)$, and a weak relation between TI and TSH level $\left(\mathrm{R}^{2}=10 \%, p<0.05\right)$. This study proved that a collagen scaffold can be successfully used in alveolar crest regeneration, especially in patients with a high normal level of TSH in the middle-aged population.
\end{abstract}

Keywords: oral surgery; collagen scaffold; intraoral radiograph; image analysis; jaw bone; augmentation; bone substitute material; bone turnover; thyroid-stimulating hormone; densitometry

\section{Introduction}

Systemic conditions affect bone structure [1]. It has been shown that more than $50 \%$ of people affected by chronic diseases arbitrarily discontinue therapy within one year [2], intensifying the impact of this known relationship. Takaishi et al. [3] suggested that the possible association between alveolar bone mineral density (measured in intraoral radiographs) and poor general mineral condition was a predictor of vertebral fracture risk. This study was based on the evaluation of optical density. However, the analysis of the optical density histogram does not give much information about bone structure [4], and the correct bone structure provides knowledge about the condition of the bone (i.e., whether it is living and healthy) [5]. In order to extract this information from an intraoral radiograph, a second-order feature is needed. Such features are named texture features and are proposed as objective measures for radiological bone structure monitoring [6]. Based on the analysis of radiological textures, there is a chance of finding compounds of the general mineral condition within the structure of the alveolar bone [7].

Augmentation of the alveolar crest is one of the basic ways to improve bone conditions in the oral cavity before its prosthetic treatment. The regeneration of bone tissue allows clinicians to place 
implants or miniscrews with greater diameter and length [8], thus allowing better clinical results and durability [9]. The basic biological mechanism used is osteoconduction. It requires scaffolding made of biomaterial on which a new bone is formed, gradually filling the bone defect, e.g., the alveolus. Scaffolding can be built of amorphous calcium phosphate, calcium carbonate, biologically active glass, crystalline calcium phosphate, fluorohydroxyapatite, collagen, or a mixture of collagen and calcium phosphate [10-12]. These are usually highly porous granules that are easily spilled in the operating field, but collagen is available in the form of a sponge that can easily be stabilized in the alveolus; hence, there is interest in the collagen-guided augmentation of the alveolar crest.

The aim of this study is evaluation of the influence of selected systemic factors on the formation of bone structure in places of its collagen augmentation within the alveolar crest.

\section{Materials and Methods}

The study was approved by the University Ethical Committee RNN/485/11/KB. Forty-two patients were included in this study (age $50 \pm 14$ years, 21 females and 21 males, and generally healthy). All 42 patients underwent tooth removal with local anesthesia ( $4 \%$ articaine with 1:100,000 adrenaline, $3 \mathrm{M}$ ESPE AG, Seefeld, Germany).

Inclusion criteria involved two-dimensional radiographs taken immediately after surgery and 12 months later and laboratory tests to check hormone, ion, and vitamin levels: parathormone (PTH, where norm is 10 to $60 \mathrm{pg} / \mathrm{mL}$ ), thyrotropin (TSH), where norm is $0.23-4.0 \mu \mathrm{U} / \mathrm{mL}$; calcium in serum $\left(\mathrm{Ca}^{2+}\right)$, where norm is $9-11 \mathrm{mg} / \mathrm{dL}$; glycated hemoglobin $(\mathrm{HbA} 1 \mathrm{c})$, where norm is $<5 \%$; and vitamin $25(\mathrm{OH}) \mathrm{D}_{3}(\mathrm{D} 3)$, where norm is $31-50 \mathrm{ng} / \mathrm{mL}$. Spine densitometry, where T-score can be examined, was also considered. T-score shows the ratio between bone mineral density (BMD) of the examined patient to average BMD for young patients. Normal value for normal bone is $>-1.0$, osteopenia is indicated by values between -1.0 and -2.5 , and scores $<-2.5$ indicate osteoporosis.

Exclusion criteria included a lack of X-rays, defective X-ray images in the visual assessment, lack of laboratory test, complications after surgery, and noncontrolled general diseases. A limitation of the study is that laboratory tests were checked before the surgery and authors assumed that laboratory-tested levels did not change.

Two-dimensional X-ray images were taken immediately after the surgery $(00 \mathrm{M})$ and 12 months after the surgery $(12 \mathrm{M})$. The Digora Optime radiography system was used to take intraoral X-ray images (TYPE DXR-50, SOREDEX, Helsinki, Finland). The radiographs were taken in the standardized way [13] with the following parameters: $7 \mathrm{~mA}, 70 \mathrm{mV}$, and $0.1 \mathrm{~s}$ (the focus apparatus was from Instrumentarium Dental, Tuusula, Finland). Positioners were used to take images repeatably with a $90^{\circ}$ angle of X-ray beam to the surface of phosphor plate. Texture of X-ray images were analyzed in MaZda 4.6 software, developed by University of Technology in Lodz [14], to check how the features changed over the 12 months of observation.

Data were divided into two groups: the experimental group with collagen scaffold applied $00 \mathrm{M}$ and $12 \mathrm{M}$ (Figure 1), and reference group with intact normal bone. The regions of interest (ROIs) were normalized $(\mu \pm 3 \sigma)$ to share the same average $(\mu)$ and standard deviation $(\sigma)$ of optical density within the ROI. Selected image texture features (entropy and difference entropy from the co-occurrence matrix and long-run emphasis moment from the run-length matrix) in ROIs were calculated for reference bone and for bone with collagen scaffold applied:

$$
\begin{aligned}
& \text { Entropy }=-\sum_{i=1}^{N g} \sum_{j=1}^{N g} p(i, j) \log (p(i, j) \\
& \text { DifEntr }=-\sum_{i=1}^{N g} p_{x-y}(i) \log \left(p_{x-y}(i)\right)
\end{aligned}
$$


where $\Sigma$ is sum, $N g$ is the number of levels of optical density in the radiograph, $i$ and $j$ are optical density of pixels that are 5 pixels distant from one another, $p$ is probability, and log is common logarithm [6].

$$
\text { LngREmph }=\frac{\sum_{i=1}^{N g} \sum_{k=1}^{N r} k^{2} p(i, k)}{\sum_{i=1}^{N g} \sum_{k=1}^{N r} p(i, k)}
$$

where $\Sigma$ is sum, $N r$ is the number of series of pixels with density level $i$ and length $k, N g$ is the number of levels for image optical density, $N r$ is the number of pixels in series, ad $p$ is probability $[15,16]$. These three equations were subsequently used for the Texture Index construction [12]. Finally the Texture Index (TI) and Bone Index (BI), which represent the ratio of the measure of diversity of the structure observed in the radiograph to the measure of the presence of uniform longitudinal structures, were calculated:

$$
\begin{gathered}
\text { Texture index }=\frac{\text { Entropy }}{\text { LngREmph }}=\frac{\left(-\sum_{i=1}^{N g} \sum_{j=1}^{N g} p(i, j) \log (p(i, j))\right) \sum_{i=1}^{N g} \sum_{k=1}^{N r} p(i, k)}{\sum_{i=1}^{N g} \sum_{k=1}^{N r} k^{2} p(i, k)} \\
\text { Bone Index }=\frac{\text { DifEntr }}{\text { LngREmph }}=\frac{\left(-\sum_{i=1}^{N g} p_{x-y}(i) \log \left(p_{x-y}(i)\right)\right) \sum_{i=1}^{N g} \sum_{k=1}^{N r} p(i, k)}{\sum_{i=1}^{N g} \sum_{k=1}^{N r} k^{2} p(i, k)}
\end{gathered}
$$

The index defined in this way (Equation (5)) was taken as a measure of bone regeneration. The Shapiro-Wilk test was used for normality testing. The average values of the texture features were compared by Student's $t$-test when normal distribution was confirmed, or Mann-Whitney (Wilcoxon) $\mathrm{W}$-test was used to compare medians when non-normal distribution was found. Comparisons between different general mineral condition parameters were performed with the one-way ANOVA or the Kruskal-Wallis test depending on the presence of normal distribution. Simple regression analysis was also done for the investigation of relationships between general mineral condition parameters and radiological texture features. When $p<0.05$, it was assumed that the difference was statistically significant. Stargraphics Centurion 18 ver.18.1.12 (StarPoint Technologies, Inc., Addison, TX, USA) was used for statistical analyses.

\section{Results}

Since the $p$-value is greater than or equal to 0.05 , there is not a statistically significant difference between the medians at the 95\% confidence level in Mann-Whitney (Wilcoxon) W-test for TI immediately after collagen implantation ( $\mathrm{W}=941, p=0.601)$; this was also the case for $\mathrm{BI}(\mathrm{W}=1094, p=0.058)$. On the contrary, after 12 months, a significantly lower value was found for both indices compared to the reference bone: for TI, $t=-2.189$ and $p<0.033$; for $\mathrm{BI}, t=-3.041$ and $p=0.004$ (Table 1 ). The variables describing BI are shown in Table 2.

Table 1. Calculated Bone Index (BI) and Texture Index (TI) in intraoral radiographs.

\begin{tabular}{ccccc}
\hline Index & $\mathbf{0 0 ~} \mathbf{M}$ & $\mathbf{1 2} \mathbf{M}$ & REF & Difference to Reference \\
\hline BI & $0.73 \pm 0.17$ & $0.65 \pm 0.22$ & $0.80 \pm 0.14$ & $p<0.01$ for $12 \mathrm{M}$ \\
TI & $1.66 \pm 0.34$ & $1.51 \pm 0.41$ & $1.72 \pm 0.28$ & $p<0.05$ for $12 \mathrm{M}$ \\
\hline
\end{tabular}

Abbreviations: $00 \mathrm{M}$, collagen implantation site immediately after surgery; $12 \mathrm{M}$, collagen implantation site 12 months after surgery; REF, reference trabecular bone. 
$00 \mathrm{M}$

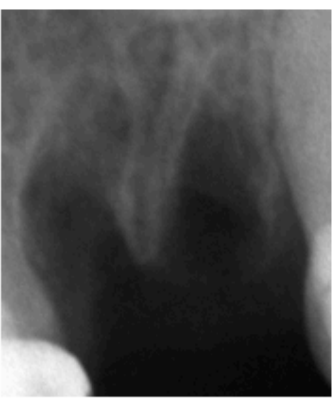

Raw RTG (a)
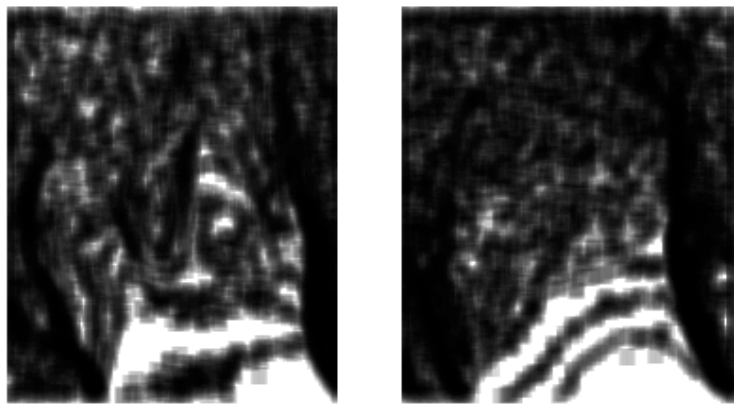

DifEntr (c)

Fusion (d)
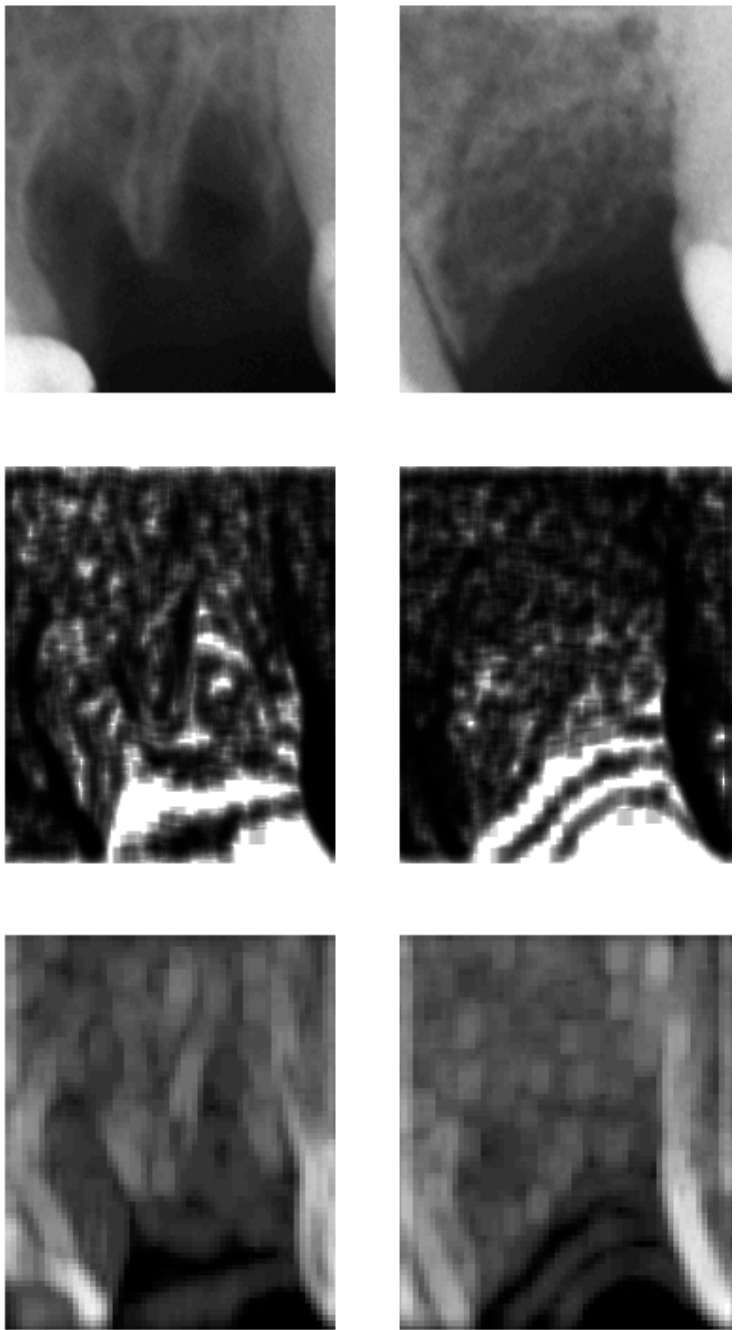

$12 \mathrm{M}$

LngREmph (b)
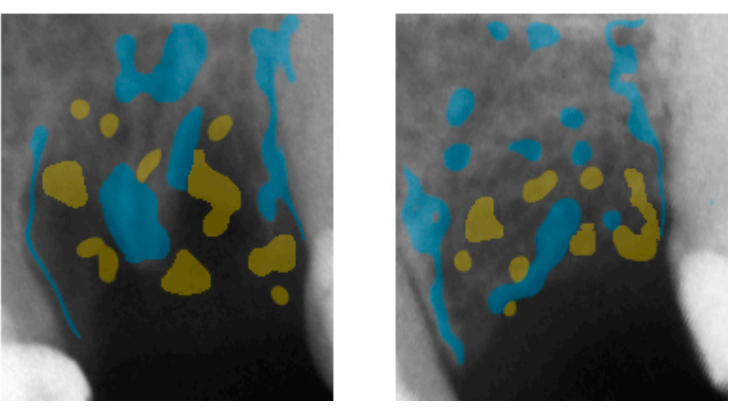

Figure 1. Collagen-guided alveolar crest augmentation. Raw RTG (a): intraoral radiograph immediately after collagen implantation into the alveolar (00 M) and at a 12-month follow-up (12 M). LngREmph (b): a map of the occurrence of long chains of pixels of similar optical density; brighter fields indicate more of such occurrences in the X-ray image. DifEntr (c): map of regions with chaotically arranged small elements recorded in the X-ray; brighter places indicate a more chaotic microstructure. Fusion (d): the application of places on the raw $X$-ray which represent the largest occurrence of long pixel chains (yellow $=$ high LngREmph) in the alveolar crest and the most chaotic places (blue $=$ high DifEntr). Please note that yellow areas do not coincide with blue areas. This is due to the detection of the different structurally different alveolar regions, i.e., LngREmph = radiolucent regions = soft tissue, while DifEntr $=$ trabecular regions $=$ bone. 
Table 2. Investigated parameters of the general mineral condition.

\begin{tabular}{ccccccccc}
\hline Summary Statistic & T-Score & PTH & D3 & Ca & TSH & D3.Ca/PTH & D3/PTH & lgSQRT Ca/PTH \\
\hline Average \pm & $-0.36 \pm 1.33$ & $38.95 \pm 16.77$ & $23.39 \pm 10.89$ & $9.71 \pm 0.40$ & $1.86 \pm 0.91$ & $6.70 \pm 3.91$ & $0.70 \pm 0.42$ & $-0.28 \pm 0.10$ \\
Stnd.deviation & -0.2 & 37.25 & 20.92 & 9.61 & 1.81 & 4.90 & 0.51 \\
Median & -2.9 & 11.7 & 10.0 & 8.8 & 0,4 & 2.3 & 0.2 & -0.30 \\
Minimum & 2.9 & 96.3 & 54.0 & 10.7 & 5.05 & 15.5 & 1.66 & -0.5 \\
Maximum & 5.8 & 84.6 & 44.0 & 1.9 & 4.66 & 13.2 & 1.42 & 0.02 \\
Range & 0.36 & $3.09^{*}$ & $2.36^{*}$ & 1.33 & $3.32^{*}$ & 1.55 & 1.65 & 1.75 \\
Stnd. skewness & -0.12 & $3.41^{*}$ & 1.60 & -0.05 & $3.64^{*}$ & -0.61 & -0.49 \\
Stnd. kurtosis & & & & & & & 1.18 \\
\hline
\end{tabular}

Abbreviations: PTH, parathormone; D3, vitamin $25(\mathrm{OH}) \mathrm{D}_{3} ; \mathrm{Ca}$, calcium concentration in serum; TSH, thyroid-stimulating hormone; $\mathrm{lg}$, common logarithm (used for normalization); SQRT, square root (used for normalization); *, lack of normal distribution.

TI calculated for reference bone is not dependent on age, T-score, PTH, vitamin D3, or Ca, but a relatively weak relationship to TSH serum level was noted (linear regression model $p<0.05, \mathrm{CC}=-0.32$, $\mathrm{R}^{2}=10 \%$ ) for the reference bone in alveolar crest. In contrast, $\mathrm{BI}$ is completely independent of the biochemical parameters tested. Both indices have a normal distribution in the given population, i.e., TI: Shapiro-Wilk test $0.98, p=0.48$; BI: Shapiro-Wilk test $0.98, p=0.66$ (Figure 2).

Normal Probability Plot with $95 \%$ limits
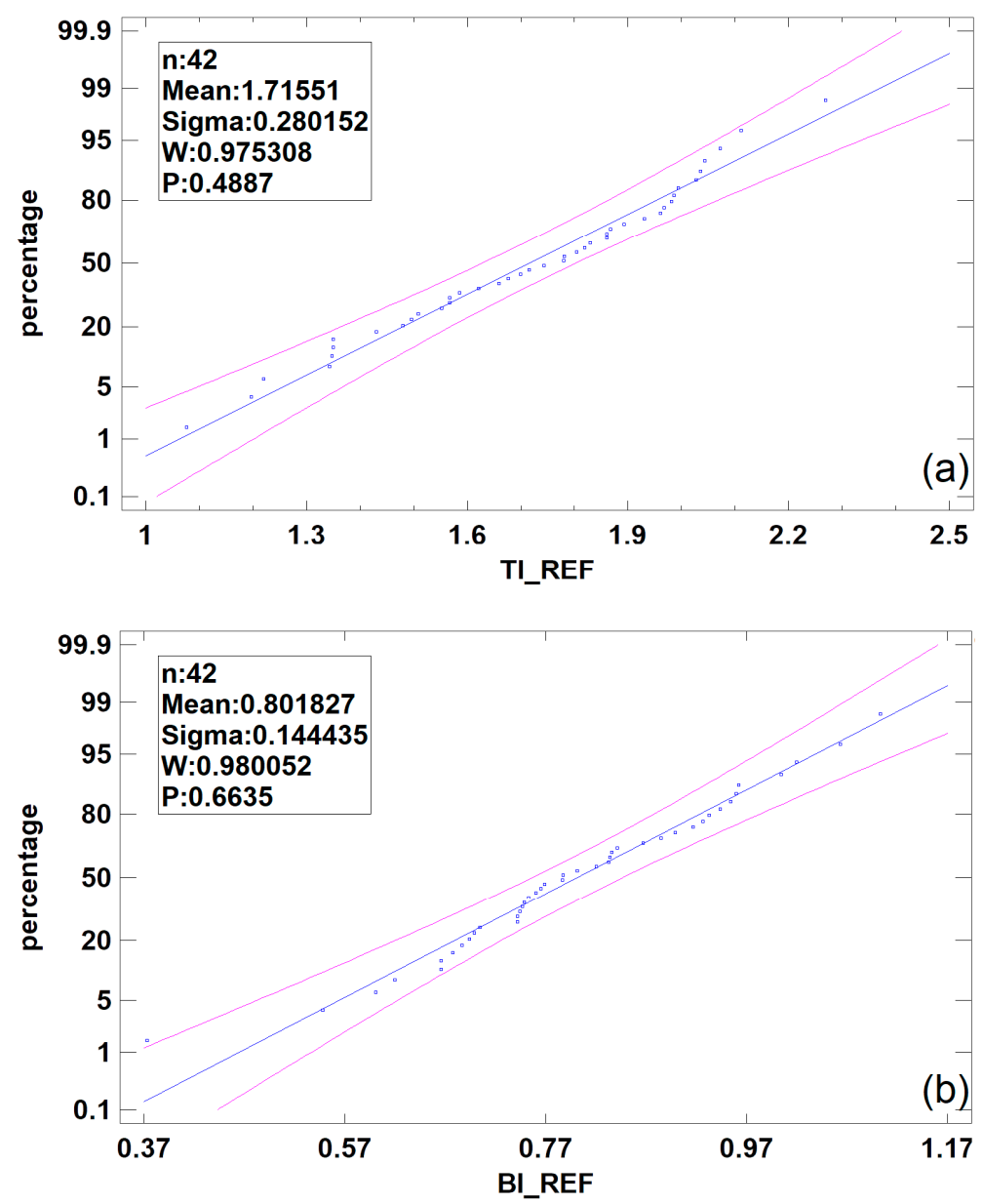

Figure 2. Distribution of Texture Index (TI)—(a) and Bone Index (BI)-(b). Note: $n$, number of cases; $\mathrm{W}$, Shapiro-Wilk test result; $\mathrm{P}$, statistical significance.

A moderately strong relationship was found between BI and the patient's age $(p<0.001)$; a similar relationship was also found between BI and TSH serum level $(p<0.05)$ (Table 3). Older patients had higher BI values $(B I=1 /(-0.583587+110.582 /$ Age $)$ ). Similarly (Figure 3$)$, in patients with higher 
serum TSH concentrations (but remaining in the physiological norm), higher values of this index were observed $\left(\mathrm{BI}=\operatorname{sqrt}\left(0.330722+0.0293364 * \mathrm{TSH}^{\wedge} 2\right)\right)$. Neither BI $(p=0.688)$ nor TI $(p=0.961)$ were statistically related to osteopenia defined on the basis of T-score $(<-1.0)$ in the tested group of patients.

Table 3. The relationship of the 12-month bone regeneration outcome, expressed as BI, to general mineral condition.

\begin{tabular}{cccc}
\hline Parameter & CC & $\mathbf{R}^{\mathbf{2}}$ & $\boldsymbol{p}$ \\
\hline Age & 0.81 & $65 \%$ & $0.0003^{*}$ \\
T-Score & 0.37 & $14 \%$ & 0.260 \\
PTH & 0.05 & $0.3 \%$ & 0.852 \\
D3 & 0.52 & $27 \%$ & 0.234 \\
Ca & -0.43 & $18 \%$ & 0.111 \\
TSH & 0.51 & $26 \%$ & $0.049 *$ \\
D3.Ca/PTH & -0.36 & $13 \%$ & 0.428 \\
D3/PTH & -0.34 & $12 \%$ & 0.450 \\
lgSQRT_Ca/PTH & -0.29 & $8 \%$ & 0.294 \\
\hline
\end{tabular}

Abbreviations: $\mathrm{CC}$, correlation coefficient; $\mathrm{R}^{2}$, percentage of data explained by the model; $p$, statistical significance level; PTH, parathormone; D3, vitamin $25(\mathrm{OH}) \mathrm{D}_{3} ; \mathrm{Ca}$, calcium concentration in serum; TSH, thyroid-stimulating hormone; lg, common logarithm (used for normalization); SQRT, square root (used for normalization); ${ }^{*}$, statistical significance.

Plot of Fitted Model

$\mathrm{BI}=1 /(-0.583587+110.582 / \mathrm{Age})$

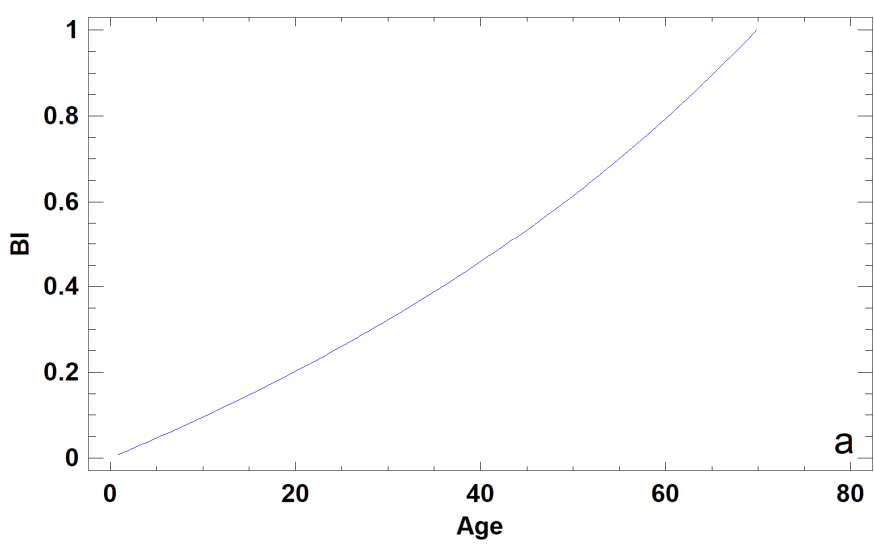

Plot of Fitted Model

$\mathrm{BI}=\operatorname{sqrt}\left(0.330722+0.0293364^{*} \mathrm{TSH}^{\wedge} 2\right)$

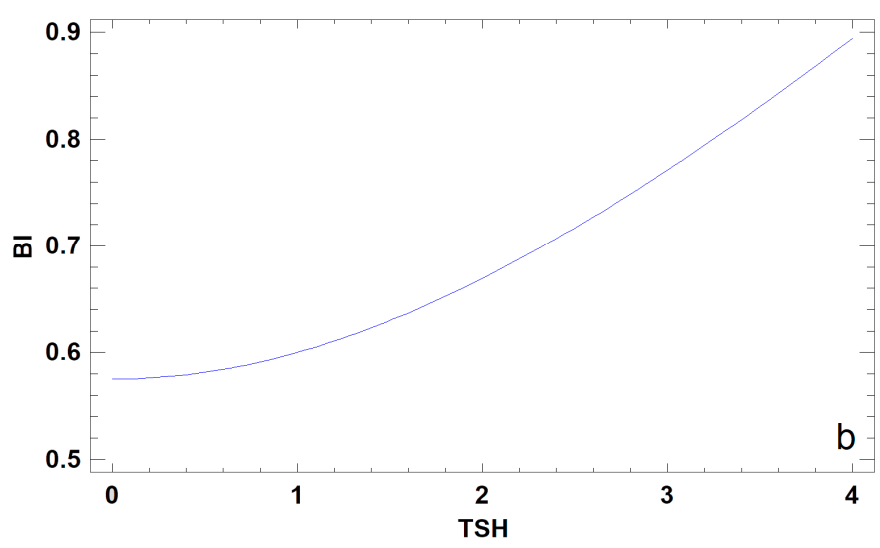

Figure 3. The models of simple regression describing the relationship of the 12-month bone regeneration outcome, expressed as BI calculated from intraoral radiographs, to patient's age (a) and TSH level (b) $(p<0.05)$. 


\section{Discussion}

The assessment of the distribution of sites with high LngREmph and high DifEntr values leads to interesting findings. Firstly, these sites never overlap (Figure 1). Secondly, the LngREmph mainly indicates those places in the intraoral radiograph where trabeculae in the alveolar bone are not visible. Contrarily, DifEntr indicates the sites where a dense network of trabeculae is located. Thus, entropy measuring is a good bone tissue marker [6], contrary to LngREmph which is a good marker of bone atrophy. Thirdly, the known Texture Index [12], defined as the ratio of the entropy of a bone image to the long run-length emphasis moment, is a good indicator to be used in the search for newly regenerated bone or the location of reflexive bone in the alveolar process. The above observations lead to an attempt to calculate a modified texture index as a ratio of DifEntr to LngREmph. This modified texture index is called the Bone Index (BI). Both indices do not indicate that collagen implantation sites are different from the reference bone on the day of surgery. However, BI is on the threshold of significance $(p=0.058)$. This can be seen as a positive feature of BI sensitivity because it is clear that there is not yet normal bone at the site after surgery. The lack of sensitivity of both indices in this range can be explained by the total translucency of the implanted collagen to the radiation creating the X-ray image and the existence of walls of normal bone overlapping the image of the surgical site in the intraoral image.

The result of crestal bone healing in a 12-month observation monitored by BI indicates that the regenerated bone is not identical to the reference one (Table 1). Nature creates bones differently than implanted collagen scaffold can $(p<0.01)$. Numerous fields without dense trabeculation after 12 months of healing can be observed (Figure 1). This may be related to the fact that the bone regenerates under stress relief conditions. However, bones loaded, e.g., by dental implants [17], are rebuilt towards compact bone. Decreasing of texture entropy in surrounding bone was observed [7].

Usually, most of the augmentation site is filled with biomaterial and not bone after several postoperational months [18]. This is especially true for hydroxyapatites [19], but it is also observed, although to a lesser extent, in tricalcium phosphates [20,21]. Therefore, the use of materials with collagen scaffolding and filled with tricalcium phosphate has greater potential than collagen alone. Such a blended material is much more similar (taking into account texture analysis) to reference bone than other substitution materials. The collagen-mineral blend implantation has a similar effect to that of collagen material (Osteovit). Contrary to collagen scaffold for bone regeneration, the augmentation result with classical granular biomaterials (tricalcium phosphates) is such that the difference cannot be detected. The reduced value of Texture Index observed in absolute values during one year, indicates the need for further observation of the effectiveness of collagen alone, as well as that of inorganic materials suspended in collagen base, despite both of them being excellent in handling bone defects [12].

The bone structure at the site of collagen implantation, as expressed by the Bone Index, is not related to the measured bone turnover parameters. However, it is related to the patient's metabolism (TSH serum level), which may indicate that bone regeneration in a short period of 12 months is not strongly influenced by the general mineral condition of a generally healthy patient (in the study, most patients were normal in terms of T-score, 11 had osteopenia, and only 2 had osteoporosis). The basic mechanisms remain unknown because TSH did not affect the proliferation or differentiation of primary osteoblasts, nor did it activate the cAMP (cyclic adenosine monophosphate), p38 mitogen-activated protein kinase, or protein kinase B signal pathways [22]. TSH in vitro inhibited osteoblastogenesis and decreased expression of type I collagen, bone sialoprotein, and osteocalcin [23]. Sampath et al. [24] and Baliram et al. [25] showed that TSH stimulates osteoblast differentiation and function. In humans, TSH also stimulated proliferation and differentiation, as measured by alkaline phosphatase, and increased expression of IGF-1 (Insulin-like Growth Factor 1) and IGF-2 (Insulin-like Growth Factor 2) mRNA, along with complex regulatory action on IGF-binding proteins (insulin-like growth factor-binding protein) and their protease s [26]. Overall, the findings have been interpreted as suggesting that changes in TNF $\alpha$ (Tumor Necrosis Factor $\alpha$ ), RANKL (Receptor Activator for Nuclear Factor Ligand), OPG (Osteoprotegerin), and IL-1 (Interleukin 1) signaling in response to TSH 
may be mediated by the alternative G-protein rather than by cAMP $[23,27,28]$. Thus, although the TSH receptor is expressed in osteoblasts building the alveolar crest, data from in vitro studies are contradictory, suggesting that TSH may inhibit, amplify, or have no effect on the differentiation of osteoblasts and their function. Moreover, the physiological pathway of the second messenger, which lies below the active TSH receptor in the osteoblasts [29], has not yet been determined. Unfortunately, a different signaling pathway is the key one regulating craniofacial patterning. The bone morphogenic protein (BMP) pathway regulates development of mineralized structures such as the jawbone [30]. Thus, BMP signaling contributes both to shape and functionality of our facial features [31]. BMP signaling also regulates jawbone remodeling and healing [32]. BMP function will contribute to our ability to rationally manipulate this signaling network in the context of tissue engineering. It seems impossible for the TSH and BMP signaling pathways to be intertwined somewhere in the jaw area.

Patients with higher levels of TSH (untreated hypothyroidism) can reveal worse bone regeneration healing results. This may be due to a slowed bone formation process and bone resorption process [33]. This can be considered as confirmation of the results in our study, where good results in the bone regeneration process are related with higher levels of TSH but are still in the norm.

The first link between osteoporosis and bone loss in the oral cavity was discovered sixty years ago [34]. This association is still a contentious issue because of mixed results in the literature, and studies have yet to show conclusively an association between osteoporosis and changes to the residual alveolar ridge $[35,36]$. When compared with other risk factors (age, body size, bone turnover markers, and T-score), alveolar bone mineral density measurements showed a higher association with vertebral and long bone fractures than lumbar bone mineral density and could successfully identify those patients who had sustained a fracture in the multivariate analysis. Assessment of alveolar bone density [3], contrary to alveolar textural features, may be a useful adjunct method for assessing patients of advanced age during routine dental examinations to monitor the clinical picture and the potential course of osteoporosis. It seems this does not apply to younger patients, i.e., the ones studied in this experiment.

It is worth noting that the Bone Index has a very strong correlation to the age of the patient (correlation coefficient $=81, p<0.001$ ). This suggests the influence of general health on the structure of the regenerated bone. This study cannot clarify this relationship because of the relatively small group of examined patients, short observation time, and limited panel of performed biochemical tests. The potential reasons in tested patients may include genetic factors [37,38], poor dietary intake [39,40], lower physical activity [41-43], or decreased level of immune host response in older patients. Jabłońska, in her study, showed that the strain placed on the immune system over time leads to inefficiency that increases with age, with cellular and humoral immunity decreasing as one gets older. Thus, it can only be assumed that low host immune response to substitution material proteins (i.e., collagen) allows for good regeneration of bone defects versus an adverse immunological reaction against xenogenic proteins, but this requires a larger group of observed patients to determine [44]. Another explanation for the difficulty in discovering the influence of general mineral condition on the structure of jaw bones is the specificity of the dental system, i.e., overwhelming local factors. It is worth recalling that within the oral cavity, the skeleton is closer to the external world than all other body locations. The gingiva covers the bone with a layer as thin as $1 \mathrm{~mm}$. Nowhere else is the skeleton this close to the external environment. The presence of teeth growing out of the skeleton and protruding into the external environment, the pressure of multiple chewed foods, the antigenic effect of foods, and the bacterial flora of the oral cavity must significantly affect the structure of the deeper lying bone as well as the process of controlled bone regeneration.

The limitations of this study are a small sample, two-dimensional texture analysis, and a limited panel of biochemical tests. Extrinsic collagen (xenogenic) may cause an adverse reaction, which would not be without an effect on bone regeneration. 


\section{Conclusions}

Within the limitations of the present report, it has been demonstrated that the bone formed in the site of regeneration based on a collagen scaffold does not reproduce bone with identical structure to bone formed during ontogenesis. However, as with other bone substitute materials, the collagen scaffold can be used for further dental treatment procedures. The effect of general mineral condition is substantially modified by local factors specific to the alveolar process of the jaw, although its strongest indirect representatives are responsible for a significant effect (TSH and age).

Author Contributions: Conception and design of the work, interpretation of data for the work, drafting and revising the manuscript, and final approval-M.K.; statistical analysis and approval-P.S.; data acquisition, figure preparation, and writing (review and editing) - T.W. All authors have read and agreed to the published version of the manuscript.

Funding: Medical University of Lodz grant Nos. 503-51-001-18, 503-51-002-18, 503-51-001-17, 503-51-001-19-00.

Conflicts of Interest: The authors declare no conflict of interest. The funders had no role in the design of the study; in the collection, analyses, or interpretation of data; in the writing of the manuscript, or in the decision to publish the results.

\section{References}

1. Sewerynek, E.; Horst-Sikorska, H.; Stępień-Kłos, W.; Antkowiak, A.; Janik, M.; Cieślak, K.; Marcinkowska, M.; Cegłowska, A.; Stuss, M. The role of counselling and other factors in compliance of postmenopausal osteoporotic patients to alendronate 70 therapy. Arch. Med. Sci. 2013, 9, 288-296. [CrossRef]

2. Zanchetta, J.R.; Hakim, C.; Lombas, C. Observational study of compliance and continuance rates of raloxifene in the prevention and treatment of osteoporosis. Curr. Ther. Res. 2004, 65, 470-480. [CrossRef] [PubMed]

3. Takaishi, Y.; Arita, S.; Honda, M.; Sugishita, T.; Kamada, A.; Ikeo, T.; Miki, T.; Fujita, T. Assessment of Alveolar Bone Mineral Density as a Predictor of Lumbar Fracture Probability. Adv. Ther. 2013, 30, 487-502. [CrossRef] [PubMed]

4. Obuchowicz, R.; Nurzyńska, K.; Obuchowicz, B.; Urbanik, A.; Piórkowski, A. Caries detection enhancement using texture feature maps of intraoral radiographs. Oral Radiol. 2020, 30, 275-287. [CrossRef] [PubMed]

5. Georgiadis, M.; Müller, R.; Schneider, P. Techniques to assess bone ultrastructure organization: Orientation and arrangement of mineralized collagen fibrils. J. R. Soc. Interface 2016, 13, 20160088. [CrossRef]

6. Kołaciński, M.; Kozakiewicz, M.; Materka, A. Textural entropy as a potential feature for quantitative assessment of jaw bone healing process. Arch. Med. Sci. 2015, 11, 78-84. [CrossRef]

7. Kozakiewicz, M.; Hadrowicz, P.; Hadrowicz, J.M.; Gesing, A. Can Torque Force During Dental Implant Placement Combined with Bone Mineral Density of Lumbar Spine Be Prediction Factors for Crestal Bone Structure Alterations? Dent. Med. Probl. 2014, 51, 448-457. Available online: http://www.dmp.umed.wroc.pl/ en/article/2014/51/4/448/ (accessed on 13 August 2020).

8. Sfondrini, M.F.; Gandini, P.; Alcozer, R.; Vallittu, P.K.; Scribante, A. Failure load and stress analysis of orthodontic miniscrews with different transmucosal collar diameter. J. Mech. Behav. Biomed. Mater. 2018, 87, 132-137. [CrossRef]

9. Cenkoglu, B.G.; Balcioglu, N.B.; Ozdemir, T.; Mijiritsky, E. The Effect of the Length and Distribution of Implants for Fixed Prosthetic Reconstructions in the Atrophic Posterior Maxilla: A Finite Element Analysis. Materials 2019, 12, 2556. [CrossRef]

10. Bodek, K.H.; Michalska, M.; Bodek, A.; Kozakiewicz, M. Evaluation of the use of microcrystalline chitosan and collagen membranes as carriers for the platelet derived growth factor (PDGF-BB) in the presence of amoxicillin. Curr. Issues Pharm. Med. Sci. 2013, 26, 176-182. [CrossRef]

11. Michalska, M.; Kozakiewicz, M.; Bodek, A.; Bodek, K.H. Estimation of the use of fibrin and collage membranes as carriers for platelet-derived growth factor-BB (PDGF-BB) in the presence of amoxicillin. Indian J. Biochem. Biophys. 2015, 52, 196-202.

12. Kozakiewicz, M.; Wach, T. New oral surgery materials for bone reconstruction-A comparison of five bone substitute materials for dentoalveolar augmentation. Materials 2020, 13, 2935. [CrossRef] [PubMed] 
13. Kozakiewicz, M.; Bogusiak, K.; Hanclik, M.; Denkowski, M.; Arkuszewski, P. Noise in subtraction images made from pairs of intraoral radiographs: A comparison between four methods of geometric alignment. Dentomaxillofac. Radiol. 2008, 37, 40-46. [CrossRef] [PubMed]

14. Szczypiński, P.M.; Strzelecki, M.; Materka, A.; Klepaczko, A. MaZda-A software package for image texture analysis. Comput. Methods Programs Biomed. 2009, 94, 66-76. [CrossRef]

15. Haralick, R. Statistical and Structural Approaches to Texture. Proceed IEEE 1979, 67, 786-804. [CrossRef]

16. Materka, A.; Strzelecki, M. Texture Analysis Methods-A review, COST B11 Report (Presented and Distributed at MC Meeting and Workshop in Brussels, June 1998); Technical University of Lodz: Lodz, Poland, 1998.

17. Hadrowicz, P.; Hadrowicz, J.; Kozakiewicz, M.; Gesing, A. Assessment of Parathyroid Hormone Serum Level as a Predictor for Bone Condition around Dental Implants. Int. J. Oral Maxillofac. Implant. 2017, 32, e207-e212. [CrossRef]

18. Pang, K.M.; Lee, J.K.; Choi, S.H.; Kim, Y.K.; Kim, B.J.; Lee, J.H. Maxillary sinus augmentation with calcium phosphate double-coated anorganic bovine bone: Comparative multicenter randomized clinical trial with histological and radiographic evaluation. Implant Dent. 2019, 28, 39-45. [CrossRef]

19. Ferreira Júnior, O.; Munhoz, E.A.; Segantin, J.F.; Gonçales, E.S.; Carvalho, P.S.P. Tomographic late evaluation of xenogeneic bone grafts in sockets of impacted third molars. J. Appl. Oral Sci. 2018, 26, e20170396. [CrossRef]

20. Kozakiewicz, M.; Marciniak-Hoffman, A.; Denkowski, M. Long-term comparison of application of two beta-tricalcium phosphates in oral surgery. Dent. Med. Probl. 2009, 46, 384-388.

21. Kozakiewicz, M.; Marciniak-Hoffman, A.; Olszycki, M. Comparative analysis of 3 bone substitute materials based on co-occurance matrix. Dent. Med. Probl. 2010, 47, 23-29.

22. Bassett, J.H.; van der Spek, A.; Logan, J.G.; Gogakos, A.; Bagchi-Chakraborty, J.; Murphy, E.; van Zeijl, C.; Down, J.; Croucher, P.I.; Boyde, A.; et al. Thyrostimulin regulates osteoblastic bone formation during early skeletal development. Endocrinology 2015, 156, 3098-3113. [CrossRef]

23. Abe, E.; Marians, R.C.; Yu, W.; Wu, X.B.; Ando, T.; Li, Y.; Iqbal, J.; Eldeiry, L.; Rajendren, G.; Blair, H.C.; et al. TSH is a negative regulator of skeletal remodeling. Cell 2003, 115, 151-162. [CrossRef]

24. Sampath, T.K.; Simic, P.; Sendak, R.; Draca, N.; Bowe, A.E.; O’Brien, S.; Schiavi, S.C.; McPherson, J.M.; Vukicevic, S. Thyroid-stimulating hormone restores bone volume, microarchitecture, and strength in aged ovariectomized rats. J. Bone Miner. Res. 2007, 22, 849-859. [CrossRef] [PubMed]

25. Baliram, R.; Chow, A.; Huber, A.K.; Collier, L.; Ali, M.R.; Morshed, S.A.; Latif, R.; Teixeira, A.; Merad, M.; Liu, L.; et al. Thyroid and bone: Macrophage-derived TSH- $\beta$ splice variant increases murine osteoblastogenesis. Endocrinology 2013, 154, 4919-4926. [CrossRef] [PubMed]

26. Ramajayam, G.; Vignesh, R.C.; Karthikeyan, S.; Senthil Kumar, K.; Karthikeyan, G.D.; Veni, S.; Sridhar, M.; Arunakaran, J.; Aruldhas, M.M.; Srinivasan, N. Regulation of insulin-like growth factors and their binding proteins by thyroid stimulating hormone in human osteoblast-like (SaOS2) cells. Mol. Cell Biochem. 2012, 368, 77-88. [CrossRef] [PubMed]

27. Hase, H.; Ando, T.; Eldeiry, L.; Brebene, A.; Peng, Y.; Liu, L.; Amano, H.; Davies, T.F.; Sun, L.; Zaidi, M.; et al. $\mathrm{TNF} \alpha$ mediates the skeletal effects of thyroid-stimulating hormone. Proc. Natl. Acad. Sci. USA 2006, 103, 12849-12854. [CrossRef] [PubMed]

28. Ma, R.; Morshed, S.; Latif, R.; Zaidi, M.; Davies, T.F. The influence of thyroid-stimulating hormone and thyroid-stimulating hormone receptor antibodies on osteoclastogenesis. Thyroid 2011, 21, 897-906. [CrossRef]

29. Bassett, J.H.D.; Williams, G.R. Role of Thyroid Hormones in Skeletal Development and Bone Maintenance. Endocr. Rev. 2016, 37, 135-187. [CrossRef]

30. Graf, D.; Malik, Z.; Hayano, S.; Mishina, Y. Common mechanisms in development and disease: BMP signaling in craniofacial development. Cytokine Growth Factor Rev. 2016, 27, 129-139. [CrossRef]

31. Kopf, J.; Petersen, A.; Duda, G.N.; Knaus, P. BMP2 and mechanical loading cooperatively regulate immediate early signalling events in the BMP pathway. BMC Biol. 2012, 10, 37. [CrossRef]

32. Rui, Y.F.; Lui, P.P.; Ni, M.; Chan, L.S.; Lee, Y.W.; Chan, K.M. Mechanical loading increased BMP-2 expression which promoted osteogenic differentiation of tendon-derived stem cells. J. Orthop. Res. 2011, 29, 390-396. [CrossRef]

33. Tuchendler, D.; Bolanowski, M. The influence of thyroid dysfunction on bone metabolism. Thyroid Res. 2014, 7, 12. [CrossRef] [PubMed] 
34. Groen, J.J.; Duyvensz, F.; Halsted, J.A. Diffuse alveolar atrophy of the jaw (non-inflammatory form of paradental disease) and pre-senile osteoporosis. Gerontol. Clin. 1960, 2, 68-86. [CrossRef] [PubMed]

35. Klemetti, E.; Vainio, P. Effect of bone mineral density in skeleton and mandible on extraction of teeth and clinical alveolar height. J. Prosthet. Dent. 1993, 70, 21-25. [CrossRef]

36. Manzke, E.; Chesnut, C.H., 3rd; Wergedal, J.E.; Baylink, D.J.; Nelp, W.B. Relationship between local and total bone mass in osteoporosis. Metabolism 1975, 24, 605-615. [CrossRef]

37. Sigurdsson, G.; Halldorsson, B.V.; Styrkarsdottir, U.; Kristjansson, K.; Stefansson, K. Impact of Genetics on Low Bone Mass in Adults. J. Bone Miner Res. 2008, 23, 1584-1590. [CrossRef]

38. Weaver, C.M.; Gordon, C.M.; Janz, K.F.; Kalkwarf, H.J.; Lappe, J.M.; Lewis, R.; O’Karma, M.; Wallace, T.C.; Zemel, B.S. The National Osteoporosis Foundation's position statement on peak bone mass development and lifestyle factors: A systematic review and implementation recommendations. Osteoporos. Int. 2016, 27, 1281-1386. [CrossRef]

39. Movassagh, E.Z.; Vatanparast, H. Current Evidence on the Association of Dietary Patterns and Bone Health: A Scoping Review. Adv. Nutr. 2017, 8,1-16. [CrossRef]

40. Pedone, C.; Napoli, N.; Lauretani, F.; Pozzilli, P.; Ferrucci, L.; Antonelli-Incalzi, R. Quality of diet and potential renal acid load as risk factors for reduced bone density in elderly women. Bone 2010, 46, 1063-1067. [CrossRef]

41. Modlesky, C.M.; Majumdar, S.; Dudley, G.A. Trabecular Bone Microarchitecture in Female Collegiate Gymnasts. Osteoporos. Int. 2008, 19, 1011-1018. [CrossRef]

42. Nickols-Richardson, S.M.; Modlesky, C.M.; O'Connor, P.J.; Lewis, R.D. Premenarcheal Gymnasts Possess Higher Bone Mineral Density Than Controls. Med. Sci. Sports Exerc. 2000, 32, 63-69. [CrossRef]

43. Bielemann, R.M.; Martinez-Mesa, J.; Petrucci Gigante, D. Physical activity during life course and bone mass: A systematic review of methods and findings from cohort studies with young adults. BMC Musculoskelet. Disord. 2013, 14, 77. [CrossRef] [PubMed]

44. Jabłońska, M.K. Immunoaging-Impact of aging on the components of the immune system. Gerontol. Pol. 2013, 4, 143-147.

(C) 2020 by the authors. Licensee MDPI, Basel, Switzerland. This article is an open access article distributed under the terms and conditions of the Creative Commons Attribution (CC BY) license (http://creativecommons.org/licenses/by/4.0/). 